\title{
On the relationship between stress and mental health of college students and mediating effects of social support
}

\author{
Bo Ki Pyon 1 )
}

\begin{abstract}
This study aimed to identify the relationship between stress that were experienced by college students in daily life and mental health. It also attempted to define the mediating effects of social support. For this purpose, data were gathered through questionnaires surveying 210 college students that are attending colleges in Daejeon. The data were analyed using t-test, ANOVA, regression analysis and path analysis. According to the results, the stress of college students have enormously direct influence on their mental health and it was partly mediated by social support. It means that social support has a mediating effects within the path of stress which affects the mental health. Based on these results some institutional and practical suggestions were provided: the role and function of student counseling center is consolidated to assess systematically for the vulnerability of students to stress. The case management is introduced for individual approach to identify the risk and protection factors. It is necessary to connect with local mental health center to provide integrated services.
\end{abstract}

keywords : stress, mental health, social support, mediating effect

\section{Introduction}

College students, who are in the later stages of adolescence or early stage of adulthood, cannot help but face the various psychosocial difficulties during the period, which are caused by achievement of development tasks, such as establishment of ego identity, establishment of social relationships and psychological separation from parents[1]. Especially, a good many university students in Korea are under a lot of stress caused by competitive educational system, anxieties about choice of career and future, which are raised by job crunch, including economic pressures. Such stresses and strains lead to psychological maladjustment, including depression, anxiety and frustration. And in extreme cases, the stresses threatens their mental health seriously so that those problems may result in suicides. We may analyze the situation in the study results, in which it was concluded that the level of stress felt by Korean university students was very high, and the number of university students with various psychological problems was sharply increasing[2], and finally the $70 \%$ of all suicides among university students was caused by mental illness.[3] Regarding the mental health, the WHO has

Received(October 02, 2017), Review Result(1st: October 22, 2017, 2nd: November 29, 2017), Accepted(December 10, 2017)

${ }^{1}$ Dept. of Social Welfare, Mokwon Univ., 88 Doan-dong Seo-gu , Daejon, Korea

email : bkpyon@ hanmail.net 
announced that the best health condition is defined as the state in which individuals can recognize their own ability, dealing with stresses adequately in their daily life, and contribute to society by working productively. In this respect, mental health can be defined as an indispensable factor for normal performance of social functions and roles, as well as growth, development and well-being of individuals. As a result, stresses experienced by Korean university students and the mental health problems caused by the stresses may lead to huge social cost as the stresses may bring about negative consequences[4]. Accordingly, it is required to prepare urgent countermeasures against the mental health problems of university students, and pay attention to the mechanism that may reduce the impact of stress on mental health. In this regard, a number of internal and external research results have suggested that social support may have positive effects on mental health[5-7]. Rectifying the concept of social support, Cohen \& Hoberman(1983) defined it as a positive resource that could be derived from relationship formed by an individual[8]. And Tboits(1982), who defined the social support as satisfaction of personal desire for love recognition and belonging, argued that such desires could be satisfied through social support provided by neighbors because humans have a common desire that could be satisfied only through social interaction with others[9].

Regarding stress, classifying stress coping behaviors into positive approach and negative approach, Lazarus(1981) defined the social support as a positive approach, in which the cause of stress could be clarified and external support required to solve the stress factor could be obtained by confronting with stresses[10]. According to the results of the study carried out by House and Kahn(1981), a social support seemed to prevent or reduce the occurrence of stress, satisfy the needs of individuals and promote their health, so it could buffer the negative impact caused by stress[11]. And also, Bolger, Zuckman \& Kessler(2000) argued that individuals could be provided with necessary information required to adapt themselves to the environment through social support, improving their adaptability to the environment, so that the social support could help to overcome stresses[12].

Regarding the relationship with mental health, the results of study carried out by Robinson, Garber \& Hilsman(1995) showed that social support produced a buffering reaction between stress and mental health, so that social support could be regarded as a positive resource that could help cope with accidents or situations causing psychological problems[13]. And according to the study carried out by Dumont and Provost(1999), the higher the level of perception on social support, the higher the level of psychological stability and the more positive way of thinking, and in the reverse situation the person in question was more vulnerable to stress, experiencing more psychopathological problems[14].

Some domestic researches showed that social support played a role as a moderating factor for psychological maladjustment. According to Jeon Sin-hyun(2012), a person provided with more social support experienced less depression, and social support mitigated the influence of stress and negative incidents on depression as the social support itself had a direct effect on depression or anxiety[15]. Kim Sin-young and Choi Gyu-man(2013) 
reported in their study that the level of psychological pain rose due to sensitive reaction to stress when a person in stressful situation could not be provided with enough social support[16]. Especially, social support seemed to have a mitigating effect on suicide prevention, which was reported in the studies regarding the process of suicide attempt due to long-term depression and frustration[17]. With this background, this study is aimed at presenting an effective policy-based approach and practical method for the promotion of mental health of university students by verifying the mediating effects of social support on the relationship between mental health and stress experienced by them.

\section{Method of Study}

\subsection{Subjects of survey}

The subjects of this study were composed of 210 male and female university students from randomly selected four-year universities located in Daejeon City. And the subjects were asked to fill out a self-assessment questionnaire, so that all the questionnaire responses could be used as data for analysis.

\subsection{Tools of study}

\subsubsection{Life stress}

In order to measure life stress, the stress measurement scales developed by Jeon Kyeom-ku(2000) was applied after modification and supplementation[18]. As for the overall reliability, the Cronbach's a efficiency was .935 .

\subsubsection{Mental health}

In order to measure mental health, the Symptom Checklist-90-Revised (SCL-90-R) was applied, which was created by the standardization of 'Symptom checklist 90 known as a self-report multidimensional symptom checker developed by Derogatis(1973)[19]. The standardization was carried out in accordance with the actual condition of Korea by Kim Gwang-il and Kim Jae-hwan(1984)[20]. As for the overall reliability, the Cronbach's a efficiency was .979 .

\subsubsection{Social support}

The scales developed by Park Ji-won(1985) was used to measure the social support[21].

In this study, only the total of social support was used. And as for the overall reliability, the Cronbach's a efficiency was .923 . 


\subsubsection{Socio-demographic variables}

The socio-demographic variables consisted of eight questions, including gender, school year, religion and economic condition and others.

\subsubsection{Data analysis}

In this study, the data was analyzed by using the SPSS18.0K, which is a statistics program. Firstly, the frequencies and percentages were calculated by implementing technical statistic analyses on subjects. Then, in order to examine the difference and correlation among the groups, a cross tabulation analysis(Chi-square), t-test and ANOVA were carried out. In addition, a correlation analysis, simple regression, multiple regression and hierarchical regression analysis were carried out so that the multi-collinearity could be verified. Finally, a path analysis was implemented in order to verify the mediating effect of variables.

\section{Contents}

\subsection{Characteristics of subjects}

[Table 1] Socio-demographic characteristics of subjects

\begin{tabular}{|c|c|c|c|}
\hline Name of variables & Division & Frequency & Percentage(\%) \\
\hline \multirow{3}{*}{ Gender } & Male & 69 & 33.0 \\
\cline { 2 - 4 } & Female & 141 & 67.0 \\
\hline \multirow{4}{*}{ School year } & Freshman & 65 & 31.0 \\
\cline { 2 - 4 } & Sophomore & 13 & 6.0 \\
\cline { 2 - 4 } & Junior & 115 & 55.0 \\
\cline { 2 - 4 } & Senior & 17 & 8.0 \\
\hline \multirow{4}{*}{ Age } & Under 19 years old & 49 & 23.0 \\
\cline { 2 - 4 } & 20 & 29 & 14.0 \\
\cline { 2 - 4 } & 21 & 50 & 24.0 \\
\cline { 2 - 4 } & 22 & 48 & 23.0 \\
\cline { 2 - 4 } & 23 and up & 34 & 16.0 \\
\hline \multirow{4}{*}{ Pocket money level } & Well-satisfied & 6 & 3.0 \\
\cline { 2 - 4 } & Satisfied & 80 & 48.0 \\
\cline { 2 - 4 } & Average & 101 & 11.0 \\
\cline { 2 - 4 } & Unsatisfied & 23 & 0 \\
\cline { 2 - 4 } & Highly unsatisfied & 0 & \\
\hline
\end{tabular}

Table 1 shows the socio-demographic characteristics of the subjects. As for gender results, female students accounted for $67 \%$, and male students accounted for 33\%. The percentage of junior, freshman, senior and 
sophomore accounted for $55 \%, 31 \%, 8 \%$ and $6 \%$, in order of size, respectively. The average age was about 21 years old. As for economic condition, $48 \%$ of respondents seemed to have no problem in current economic condition in broad outlines. As for the religion, the students without religion accounted for $58.0 \%$, which outnumbered the students with religion by more than $10 \%$. As for the students who have a romantic relationship or not, the subjects who did not have opposite-sex friendship accounted for $54 \%$, which outnumbered the students with opposite-sex friendship by more than $10 \%$. Regarding the school work, $61.0 \%$ of the students replied that they were in the middle ranks.

\subsection{Stress, social support, mental health related to socio-demographic characteristics}

In order to identify the variation in stress, social support and mental health in accordance with socio-demographic characteristics, a t-test and ANOVA were implemented. The results are as follows.

\subsubsection{Difference in major variables according to gender}

As for the relationship between variables of stress and mental health, male students had more stress and worse mental health than female students. In the case of social support, it appeared that male students were provided with more support than females, however, there was no statistically significant differences between gender.

[Table 2] Difference in major variables according to gender

\begin{tabular}{|c|c|c|c|c|}
\hline \multicolumn{2}{|c|}{ Division } & Average & Standard deviation & $\mathrm{t}$ \\
\hline \multirow{2}{*}{ Stress } & Male & 2.3827 & .49213 & \multirow{2}{*}{$3.250^{* *}(\mathrm{p}=.002)$} \\
\cline { 2 - 4 } & Female & 2.0176 & .54518 & \multirow{2}{*}{1.807} \\
\hline \multirow{2}{*}{ Social support } & Male & 3.9039 & .42555 & \multirow{2}{*}{$3.272^{* *}(\mathrm{p}=.002)$} \\
\cline { 2 - 5 } & Female & 3.7091 & .54234 & .50653 \\
\hline \multirow{2}{*}{ Mental health } & Male & 2.3023 & .52233 & \\
\cline { 2 - 5 } & Female & 1.9424 & & \\
\hline
\end{tabular}

${ }^{* * *} \mathrm{p}<.001,{ }^{*} \mathrm{p}<.01,{ }^{*} \mathrm{p}<.05$

\subsubsection{Difference in major variables regarding existence or nonexistence of opposite-sex friendship}

The stress level of students without opposite-sex friendship appeared to be high and their mental health was bad as well, however, the level was not statistically significant. And there was no difference in the level of stress, social support, and mental health regarding existence or nonexistence of opposite-sex friendship.

[Table 3] Difference regarding existence or nonexistence of opposite-sex friendship 


\begin{tabular}{|c|c|c|c|c|}
\hline \multirow{2}{*}{ Division } & Average & Standard deviation & $\mathrm{t}$ \\
\cline { 2 - 4 } Stress & Existent & 2.2422 & .52568 & \multirow{2}{*}{-.344} \\
\hline \multirow{2}{*}{ Social support } & Non-existent & 2.2793 & .54899 & \\
\cline { 2 - 4 } & Existent & 3.8278 & .44994 & \multirow{2}{*}{-.230} \\
\hline \multirow{2}{*}{ Mental health } & Non-existent & 3.8496 & .49681 & \\
\cline { 2 - 4 } & Existent & 2.1725 & .53322 & \multirow{2}{*}{-.190} \\
\cline { 2 - 4 } & Non-existent & 2.1930 & .54466 & \\
\hline
\end{tabular}

$$
* * * \mathrm{p}<.001, * * \mathrm{p}<.01, * \mathrm{p}<.05
$$

\subsubsection{Difference in major variables regarding whether religious or not}

The students without religion appeared to have a higher stress level, and their mental health was worse. On the contrary, the students with religion appeared to be provided with more social support. In general, psychological stability based on religion must have been reflected in the analysis results. However, there was no statistically significant difference.

[Table 4] Difference regarding whether religious or not

\begin{tabular}{|c|c|c|c|c|}
\hline \multicolumn{2}{|c|}{ Division } & Average & Standard deviation & $\mathrm{t}$ \\
\hline \multirow{2}{*}{ Stress } & Religious & 2.2252 & .61319 & \multirow{2}{*}{-.562} \\
\cline { 2 - 4 } & Non-religious & 2.2890 & .47625 & \multirow{2}{*}{1.516} \\
\hline \multirow{2}{*}{ Social support } & Religious & 3.9200 & .39578 & .51831 \\
\cline { 2 - 4 } & Non-religious & 3.7814 & .63377 & \multirow{2}{*}{-.345} \\
\cline { 2 - 4 } Mental health & Religious & 2.1606 & .45923 & \\
\cline { 2 - 4 } & Non-religious & 2.2002 & & \\
\hline
\end{tabular}

$$
* * * \mathrm{p}<.001, * * \mathrm{p}<.01, * \mathrm{p}<.05
$$

\subsubsection{Difference in major variables regarding school year}

The level of stress appeared to vary according to school year. ( $\mathrm{F}=8.394, \mathrm{P}<.001)$ and the results of post-hoc test(Scheffé) on difference among school years showed that the freshman students experienced more stress than sophomore, junior students experienced more stress than sophomore, and senior students experienced more stress than freshman.

The level of social support also appeared to vary according to school year $(\mathrm{F}=2.270, \mathrm{p}<.01)$ and the results of post-hoc test(Scheffé) on difference among school years showed that the sophomore students experienced more social support than freshman, sophomore students experienced more stress than junior, and senior students experienced more stress than junior.

The level of mental health appeared to vary according to school year $(\mathrm{F}=7.035, \mathrm{p}<.001)$ and the results of post-hoc test(Scheffé) on difference among school years showed that the mental health of freshman, junior and senior students was worse than that of sophomore students. In summary the difference in stress, social support and mental health among each school year was statistically significant. 
[Table 5] Difference among school years

\begin{tabular}{|c|c|c|c|c|}
\hline \multicolumn{2}{|c|}{ Division } & Average & Standard deviation & $\mathrm{F}$ \\
\hline \multirow{4}{*}{ Stress } & Freshman(a) & 2.2019 & .29653 & \multirow{4}{*}{$\begin{array}{c}8.394^{* * *} \\
(\mathrm{a}>\mathrm{b}, \mathrm{c}>\mathrm{b}, \mathrm{d}>\mathrm{b})\end{array}$} \\
\hline & Sophomore(b) & 1.3667 & .43555 & \\
\hline & Junior(c) & 2.3960 & .58742 & \\
\hline & Senior(d) & 2.2475 & .21137 & \\
\hline \multirow{4}{*}{ Social support } & Freshman(a) & 2.2622 & .53601 & \multirow{4}{*}{$\begin{array}{c}2.270^{* *} \\
(b>a, b>c, d>c)\end{array}$} \\
\hline & Sophomore(b) & 3.7845 & .31760 & \\
\hline & Junior(c) & 4.1933 & .46608 & \\
\hline & Senior(d) & 3.7876 & .53199 & \\
\hline \multirow{4}{*}{ Mental health } & Freshman(a) & 4.1450 & .39071 & \multirow{4}{*}{$\begin{array}{c}7.035^{* * *} \\
(\mathrm{a}>\mathrm{b}, \mathrm{c}>\mathrm{b}, \mathrm{d}>\mathrm{b})\end{array}$} \\
\hline & Sophomore(b) & 3.8396 & .47358 & \\
\hline & Junior(c) & 2.1430 & .29653 & \\
\hline & Senior(d) & 1.3241 & .38067 & \\
\hline
\end{tabular}

${ }^{* * *} \mathrm{p}<.001,{ }^{*} * \mathrm{p}<.01,{ }^{*} \mathrm{p}<.05$

\subsubsection{Difference in major variables regarding satisfaction on allowance}

As for stress, there was a statistically significant difference among the groups according to the level of allowance $(\mathrm{F}=6.674, \mathrm{p}<.001)$ and the results of post-hoc test(Scheffe) showed that the stress level of dissatisfied group appeared to be higher than that of satisfied group.

In the case of social support $(\mathrm{F}=6.221, \mathrm{p}<.01)$, the results of post-hoc test(Scheffe) showed that the social support level of dissatisfied group appeared to be much lower than that of satisfied group and ordinary group.

In the case of mental health $(\mathrm{F}=7.559, \mathrm{p}<.001)$, the results of post-hoc test(Scheffe) showed that the mental health level of dissatisfied group appeared to be much worse than that of satisfied group and ordinary group.

[Table 6] Difference in level of satisfaction on allowance

\begin{tabular}{|c|c|c|c|c|}
\hline & ision & Average & Standard deviation & $\mathrm{F}$ \\
\hline \multirow{4}{*}{ Stress } & Well-satisfied(a) & 2.6600 & .68440 & \multirow{4}{*}{$\begin{array}{c}6.674^{* * *} \\
(\mathrm{~d}>\mathrm{b}, \mathrm{d}>\mathrm{c})\end{array}$} \\
\hline & Satisfied(b) & 2.1363 & .53917 & \\
\hline & Average(c) & 2.2046 & .47426 & \\
\hline & Unsatisfied(d) & 2.8400 & .35643 & \\
\hline \multirow{4}{*}{$\begin{array}{c}\text { Social } \\
\text { support }\end{array}$} & Well-satisfied(a) & 2.2622 & .53601 & \multirow{4}{*}{$\begin{array}{c}6.221^{* *} \\
(b>d, c>d)\end{array}$} \\
\hline & Satisfied(b) & 3.4267 & .02309 & \\
\hline & Average(c) & 3.9832 & .36133 & \\
\hline & Unsatisfied(d) & 3.8567 & .42779 & \\
\hline \multirow{4}{*}{$\begin{array}{l}\text { Mental } \\
\text { health }\end{array}$} & Well-satisfied(a) & 3.3818 & .71808 & \multirow{4}{*}{$\begin{array}{c}7.559^{* * *} \\
(d>b, d>c)\end{array}$} \\
\hline & Satisfied(b) & 3.8396 & .47358 & \\
\hline & Average(c) & 2.8074 & .87244 & \\
\hline & Unsatisfied(d) & 2.0547 & .50521 & \\
\hline
\end{tabular}




\subsection{Technical analysis on major variables}

A technical analysis was carried out in order to identify the overall characteristics of subjects in this study. In the case of stress and mental health, the stress level (2.26 point) was lower than the average, and the mental health level was relatively good (2.18 point), as well. Accordingly, the stress and mental health level of overall subjects may be regarded as an average level. And the social support level appeared to be higher than the average (3.83 point).

[Table 7] Technical analysis on major variables regarding subjects

\begin{tabular}{|c|c|c|c|c|c|}
\hline & $\mathrm{N}$ & Average & $\begin{array}{c}\text { Standard } \\
\text { deviation }\end{array}$ & $\begin{array}{c}\text { Minimum } \\
\text { value }\end{array}$ & $\begin{array}{c}\text { Maximum } \\
\text { value }\end{array}$ \\
\hline Stress & 210 & 2.2622 & .53601 & 1.02 & 3.68 \\
\hline Social support & 210 & 3.8396 & .47358 & 2.16 & 4.92 \\
\hline Mental health & 210 & 2.1836 & .53680 & 1.01 & 3.89 \\
\hline
\end{tabular}

\subsection{Correlation analysis among variables}

Table 8 shows the result of correlation analysis among major variables. The correlation coefficient between independent and dependent variables appeared to be very high $(\mathrm{r}=.951, \mathrm{p}<.001)$. Though the correlations among dependent variables was not high, it was concluded that the variables used in this study had no problem regarding multicollinearity because there was no value of VIF beyond 10. And the level of correlation between the social support, which played a role as a parameter, and the other two variables was low, however, it appeared to be statistically significant.

[Table 8] Analysis of correlation among major variables

\begin{tabular}{|c|c|c|c|}
\hline & Stress & Mental health & Social support \\
\hline Stress & 1 & & \\
\hline Mental health & $.951^{* * *}$ & 1 & 1 \\
\hline Social support & $-.336^{* *}$ & $-.311^{* *}$ & \\
\hline$* * * \mathrm{p}<.001,{ }^{* *} \mathrm{p}<.01,{ }^{*} \mathrm{p}<.05$ &
\end{tabular}

\subsection{Hierarchical regression analysis of variables}

In order to compare the independent variables by stages, a hierarchical regression analysis of variables was implemented as follows in Table 10. The independent variables were applied to the first stage and socio-demographic factors were applied to the second stage, so that the influence of stress and social support 
on mental health was analyzed by using them as variables.

[Table 9] Hierarchical regression analysis on mental health

\begin{tabular}{|c|c|c|c|c|c|}
\hline Factors & $\beta$ & $\mathrm{t}$ & $\beta$ & $\mathrm{t}$ & VIF \\
\hline (Constant) & & $2.500^{*}$ & & -.326 & \\
\hline Control variable & & & & & \\
\hline Age & -.197 & -1.136 & .038 & .594 & 4.027 \\
\hline School year & .242 & 1.406 & -.026 & -.425 & 3.662 \\
\hline Allowance & .180 & 1.887 & -.031 & -.897 & 1.132 \\
\hline Gender $^{\mathrm{a}}$ & .231 & 2.017 & .025 & .551 & 1.944 \\
\hline Stress & & & .953 & $24.949 * * *$ & 1.428 \\
\hline Social support & & & -.008 & -.206 & 1.555 \\
\hline $\mathrm{R}$ & \multicolumn{2}{|c|}{.394} & \multicolumn{2}{|c|}{.951} & \\
\hline $\mathrm{R}^{2}\left(\operatorname{Adj} \mathrm{R}^{2}\right)$ & \multicolumn{2}{|c|}{$.155(.119)$} & \multicolumn{2}{|c|}{$.905(.899)$} & \\
\hline$\triangle \mathrm{R}^{2}$ & \multicolumn{2}{|c|}{.155} & \multicolumn{2}{|c|}{.750} & \\
\hline $\mathrm{F}$ & \multicolumn{2}{|c|}{$4.357^{* *}$} & \multicolumn{2}{|c|}{$147.504 * * *$} & \\
\hline Change in $F$ & \multicolumn{2}{|c|}{$4.357^{* *}$} & \multicolumn{2}{|c|}{$366.713^{* * *}$} & \\
\hline
\end{tabular}

$* * * \mathrm{p}<.001, * * \mathrm{p}<.01, * \mathrm{p}<.05$

a: The gender was used as dummy variable $($ Male $=0$, Female $=1$ )

The socio-demographic factors applied to the first stage explained the $15.5 \%$ of the variate of dependent variables, and this value implies that the $\mathrm{F}$ value was statistically significant, which was $4.357(\mathrm{p}<.01)$. The stress and social support applied to the second stage explained the $89.9 \%$ of the variate of dependent variables $(\mathrm{R} 2=0.899)$, which implied that it was statistically significant $(\mathrm{F}=147.503, \mathrm{p}<.000)$. The accumulated value R2, which was calculated by combining the two dimensions, was .905 which was statistically significant. The most important variable was stress $(\beta=.953, \mathrm{p}<.000)$.

\subsection{Regression analysis of major variables}

A regression analysis was implemented in order to identify the influence of stress which was a dependent variable on the mental health of university students. The results in Table 3.6 shows that the value of R2 was .905 , which showed $90.5 \%$ of explanation power. When $\triangle \mathrm{R} 2$ was applied to the population, it showed $90 . \%$ of explanation power. The $\mathrm{F}$ value appeared to be statistically significant. It was identified through the $\mathrm{t}$ value $(\mathrm{t}=27.220, \mathrm{p}<.000)$ that the stress had a statistically significant effect on mental health in positive direction.

[Table 10] Regression analysis of stress and mental health 


\begin{tabular}{|l|c|c|c|c|}
\hline \multicolumn{1}{|c|}{ Factors } & B & S.E & $\beta$ & $\mathrm{t}$ \\
\hline (Constant) & -.137 & .376 & & -.364 \\
\hline Control variable & & & & .561 \\
Age & .011 & .019 & .033 & -.878 \\
School year & -.022 & .025 & -.029 & .516 \\
Satisfaction & .023 & .045 & .020 & -.388 \\
Gender $^{\mathrm{a}}$ & -.012 & .031 & -.023 & $27.220^{* * *}$ \\
\hline Stress & .958 & .035 & .956 & \\
\hline $\mathrm{R}$ & \multicolumn{5}{|c|}{$.905(.900)$} \\
\hline $\mathrm{R}^{2}$ (Adj $\mathrm{R}^{2}$ ) & \multicolumn{5}{|c|}{$178.818^{* * *}$} \\
\hline $\mathrm{F}$ & \multicolumn{5}{|c|}{} \\
\hline
\end{tabular}

$* * * \mathrm{p}<.001,{ }^{* *} \mathrm{p}<.01,{ }^{*} \mathrm{p}<.05$

a: The gender was used as dummy variable(Male $=0$, Female $=1$ )

Table 11 shows the influence of stress on social support. The overall power of explanation is $32.3 \%$, and it appear to be statistically significant. It was identified through the $t$ value $(-4.007, \mathrm{p}<.000)$ that the stress had a statistically significant effect on stress in negative direction.

In short, the higher the stress, the less social support they received, or the less social support they accept from others.

[Table 11] Regression analysis of stress and social support

\begin{tabular}{|l|c|c|c|c|}
\hline \multicolumn{1}{|c|}{ Factors } & $\mathrm{B}$ & $\mathrm{S} . \mathrm{E}$ & $\beta$ & $\mathrm{t}$ \\
\hline (Constant) & 1.302 & .863 & - & 1.509 \\
\hline Control variable & & & & \\
Age & .175 & .044 & .610 & 3.968 \\
School year & -.179 & .071 & -.384 & -2.509 \\
Allowance & -.117 & .057 & -.176 & -2.042 \\
Gender $^{\mathrm{a}}$ & .515 & .103 & -.513 & 5.013 \\
\hline \multicolumn{1}{|r|}{ Stress } & -.323 & .081 & -.366 & $-4.007^{* * *}$ \\
\hline $\mathrm{R}$ & \multicolumn{3}{|c|}{$-.357(.323)$} \\
\hline $\mathrm{R}^{2}\left(\right.$ Adj $\left.\mathrm{R}^{2}\right)$ & \multicolumn{5}{|c|}{$10.434^{* * *}$} \\
\hline $\mathrm{F}$ & \multicolumn{5}{|l}{} \\
\hline
\end{tabular}

${ }^{* * *} \mathrm{p}<.001,{ }^{* *} \mathrm{p}<.01,{ }^{*} \mathrm{p}<.05$

a: The gender was used as dummy variable(Male $=0$, Female $=1)$

Table 12 shows the results of regression analysis on the influence of social support on mental health.

[Table 12] Regression analysis of social support and mental health

\begin{tabular}{|l|l|l|l|l|}
\hline Division & B & S.E & $\beta$ & t \\
\hline (Constant) & 2.834 & 1.004 & - & 2.824 \\
\hline $\begin{array}{l}\text { Control variable } \\
\text { Age }\end{array}$ & .024 & .058 & .074 & .418 \\
\hline
\end{tabular}




\begin{tabular}{|l|l|l|l|l|}
\hline \multicolumn{1}{|c|}{ School year } & .028 & 0.89 & .054 & .319 \\
Allowance & .061 & .070 & .081 & .869 \\
Gender $^{\mathrm{a}}$ & .453 & .132 & .399 & 3.446 \\
\hline Social support & -.440 & .115 & -.388 & $-3.819 * * *$ \\
\hline $\mathrm{R}$ & .518 & & \\
\hline $\mathrm{R}^{2}\left(\right.$ Adj $\left.\mathrm{R}^{2}\right)$ & $-.268(.230)$ & \\
\hline $\mathrm{F}$ & $6.900 * * *$ & \\
\hline$* * * \mathrm{p}<.001, * * \mathrm{p}<.01, * \mathrm{p}<.05$
\end{tabular}

a: The gender was used as dummy variable(Male $=0$, Female $=1$ )

According to the analysis results, the social support explained the $23.0 \%$ of mental health, and the value implied that the it was statistically significant $(\mathrm{P}<.000)$. In addition, the social support seemed to have an influence on mental health, which implied that it was statistically significant $(\mathrm{t}=-3.819, \mathrm{p}<.000)$.

Figure 1 shows the path diagram.

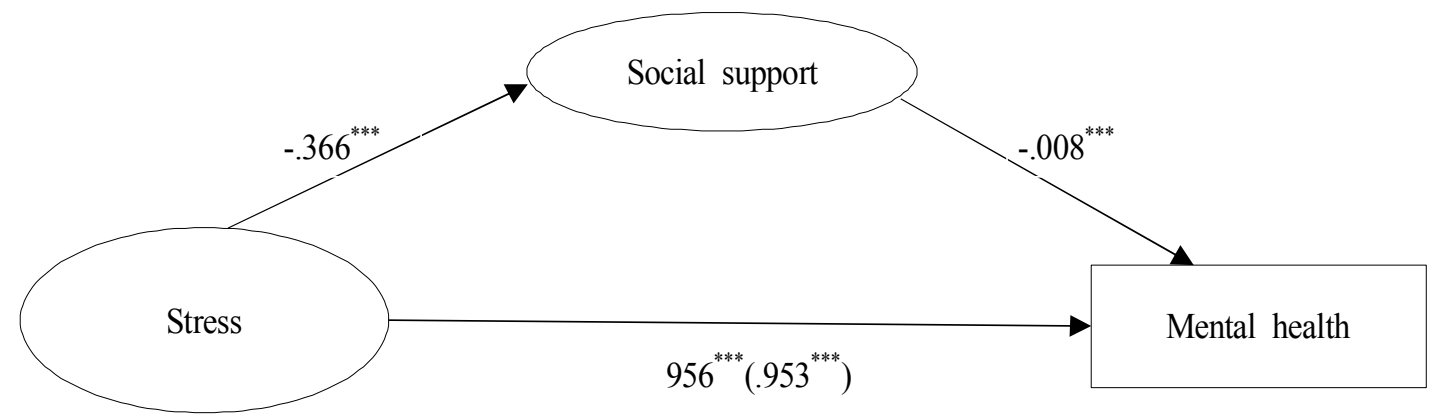

[Fig. 1] Path model of mental health

Table 13 shows the total effect of the path model in Figure 1. According to the results of analysis on path effect, the value of direct effect of stress on mental health was .956. The value indirect effect were -.366 * $-.008=.0003$, and the formula was expressed as direct $(.956)+$ indirect $(.0003)=$ interrelative effect (.394). Accordingly, it appeared that the social support functioned partially as a moderating variable

[Table 13] path effect on mental health

\begin{tabular}{|c|c|c|c|}
\hline & Direct effect & Indirect effect & Total effect \\
\hline \hline Path analysis & .956 & .0003 & .956 \\
\hline
\end{tabular}

\section{Conclusions}

According to the results of the study, the variable that best describes the mental health of university students was stress. Therefore, it is required to pay attention to the development of a system and program for the prevention and mitigation of the occurrence of stress. Most stress experienced by university students are caused by personality traits, social and economic factors, wherein it is required to establish a social and economic 
support systems.

For this reason, the roles and functions of counseling centers established in universities shall be expanded and strengthened, so that systemic assessment of all the university students can be implemented. Based on the above analysis, it is required to establish a system that can provide professional services for the students in high-risk groups, who are facing mental problems due to excessive stress, in conjunction with community mental health centers, along with preventive interventions.

For example, integrated services may be provided by introducing a case management method and establishing individualized plans based on the review of risk factors and protection factors. Depending on regional situations, community mental health centers may be established in campuses and open to local residents as well as for students, so that it can contribute to the reduction in the labeling effect by wiping out prejudices about mental health problems. 


\section{References}

[1] E. Erikson. Identity and the life cycle. New York : International Universities Press(1959).

[2] M. S. Jeon, H. J. Kim, Y. S. Park. Stress and Mental Health in Undergraduate Students. Journal of multicultural Health (2014),1 6.

[3] S. H. Kang. A study on the factors influencing the suicide ideation of University Students (2012).

[4] B.G.Druss. R.A. Rosenheck. Patterns of health care costs associated with depression and substance abuse in a national sample. Psychiatric Services (1999), 50(2), 214-218.

[5] R. M. Lim. Relationship between suicidal ideation and Stress, Despair, and Social Support in adolescence. Educational Graduate school of Chungang University(2010).

[6] Y. M. Sohn. The Effect of the adolescent's social support on their Depression. Graduate school of Sunchon National University(2012)

[7] H. Y. Choi, H. T. Chae. \& I. W. Song. The Effects of Self Esteem and Socal Support on Relationship between Elderly's stressful life events and hopelessness. Journal of Elderly Welfare (2009), 43.

[8] S. Cober \& H. M. Hoberman. Positive events and social supports of buffer of life change stress. The Journal of Applied Social Psychology, P3, 99 125(1983).

[9] P.A.Thoits.Social support and psychological well-being. In I.G. Sarason \& B.B. Sarason(Eds.), Social supprort theory, research and application(1985). The Hague : Martinus Nijhof.

[10] R.C.Lazarus. The stress and coping paradigm. In C.E. Eisendorfer, D. Cohen, A.Kleinman, \& P.Maxin(Eds.), Modeles for clinical psychopathology(1981), 177-184. NY. S. P. Medical \& scientific Books.

[11] J. S. House \& R. L. Kahn. Measure and Concepts of Social Support and Health(1985), 83 108, Academic Press.

[12] N. Bolger, A. Zuckman, R. C. Kessler, R. Invisible support and adjustment to stress. American psychological Association(2000), 79, 953-961.

[13] N. S. Robinson, J, Garber, \& R, Hilsman. Cognition and stress : Direct and moderating effects depressive versus externalizing symptoms during the Junior high education. The Journal of abnormal Psychology(1995), 104, 453-463.

[14] M. Dumont \& M. A. Provost. Resilience in adolescents : Protective role of Social Support, coping strategies, self-esteem, and Social activities on experience of stress and depression. The Journal of youth and adolescence(1999),28(3), 343-363.

[15] S. H. Choen. Relationship among Daily Stress, Social Support, Empowerment and Mental Health status by Gender in University Students. Journal of women health-nursing(2012), 18(3), 223-235.

[16] J. Y. Kim, K. H. Choi. \& J. H. Chae. Life stress, social support and social integration of north korean Refugee women in South Korea. Korean Journal of Social welfare (2013), 44(2), 33-56.

[17] Y. S. Yoo. Effects of Depression, Stress, and social support on Adolescents' Social integration. The Korea 
On the relationship between stress and mental health of college students and mediating effects of social support

Contents Society(2014),14(10), 189-197.

[18] K. K. Chon. Development of the Revised Life Stress Scale for college student . Journal of Rehabilitation Science (1988), 14(1).

[19] L.R. Derogatis, R.S. Lipman, \& L.Lovi. An Outpatient psychiatric rate scale preliminary report. Psychopharmacology Bulltin(1973),27,9-13.

[20] J. H. Kim \& K. I. Kim. A Study of korean standardization of SCL-90-R. Journal of Mental Health (1984), 4, 278-311.

[21] J. W. Park. A study on the social support scale. Dissertation. Yonsei University (1985). 